\title{
An Overview of Livestock Improvement and Extension Management Technologies: Panacea for Attaining Food Security and Industrial Development in Nigeria
}

\author{
Age, A. I. ${ }^{1}$, Anonguku, I. ${ }^{1}$ \& Unongo, E. A. ${ }^{1}$ \\ ${ }^{1}$ Department of Agricultural Extension and Communication, Federal University of Agriculture, Makurdi, \\ Nigeria \\ Correspondence: Age, A. I., Department of Agricultural Extension and Communication, Federal University of \\ Agriculture, Makurdi, Nigeria. E-mail: akosoiorbee@yahoo.com
}

Received: November 30, 2011 Accepted: February 23, 2012 Online Published: July 17, 2012

doi:10.5539/sar.v1n2p123

URL: http://dx.doi.org/10.5539/sar.v1n2p123

\begin{abstract}
This paper is an overview of livestock improvement and extension management technologies that are aimed at attainment of Food security and industrial development in Nigeria. It demystifies the concept of livestock improvement and examines the rationale for embarking on livestock improvement; and it also highlights livestock improvement management technologies that are sinequa non for attaining food security and industrial development in Nigeria. The paper recommends adoption of cross breeding of improved breeds of livestock; Pedigree selection, artificial insemination, establishment of progeny-testing stations and adoption of performance testing and livestock breeding value evaluation.
\end{abstract}

Keywords: livestock, improvement, extension, management, technologies

\section{Introduction}

Nigeria has a teeming population of 140 million people and a land mass of $923,769 \mathrm{Km}^{2}$ (NPC, 2006). This population subsists either directly or indirectly on crop products/crop-by products and animal products/ animal by-products for their nutritional needs. Albeit the productivity of crop and livestock sub-sectors of agriculture has increased tremendously in recent times, their per capita productivity seems to be dwindling considering the high population explosion in this country. In Nigeria, the livestock sub-sector has suffered more than the crop sub-sector because more attention is paid to the crop sub-sector than other sub-sectors. According to Uza et al. (1999), nutrition, diseases/pests and poor management systems and practices have for long militated against the improvement of livestock production and productivity in developing countries of the world.

This paper aims at unearthing some of the state of the art livestock improvement and extension management technologies with a view to paving the way for the attainment of food security and industrial development in Nigeria.

\section{The Concept of Livestock Improvement}

According to Age and Ahemen (2010), livestock improvement can be conceptualised as the application of scientific techniques in the production and management of new and improved breeds of livestock. It has been found that local breeds of animals have low genetic potentials, whereas the improved breeds of animals have high genetic potentials. That presupposes the more reason why the local breeds are characterised by inbreeding depression, while the improved breeds are characterised by high rate of hybrid vigour or heterosis. Application of scientific techniques in the production of animals may perhaps help in upgrading local breeds of animals.

\section{The Rationale for Adopting Livestock Improvement}

According to Age and Ahemen (2010), there are quite a number of reasons why animal breeders must adopt livestock improvement. Some of these include the following among others:

a. To increase both the quantity and quality of available animal protein in the diet of an average Nigerian.

b. To increase resistance of animals to pests and diseases.

c. To produce animals that can easily acclimatize or adapt to any adverse environmental conditions. 
d. To meet the needs of consumers in terms of height, colour, palatability and odour.

e. To enhance heterosis or productivity of animals in terms of meat, egg and milk.

f. To mitigate inbreeding depression in farm animals.

\section{Livestock Extension Improvement Technologies}

Livestock improvement can be achieved by adopting the following technologies viz, crossbreeding, pedigree selection, use of artificial insemination (AI), progeny testing, livestock performance testing and livestock breeding value evaluation.

\subsection{Cross Breeding}

This refers to the mating between two or more animals of different breeds but of the same specie. For instance, the mating between Rhode Island Red (RIR) Cock and a local hen, or the mating between N'dama bull and muturu cow, or the mating between Large White boar and Duroc sow etc are practical examples of cross breeding. According to Age and Ahemen (2010), cross breeding brings about heterosis or hybrid vigour of farm animals, produces hybrids that combine the best qualities of the original parent stock; and establishes a blood genetic base for the development of improved breeds of animals. This technology is farmers-friendly and can be adopted by even the resource poor farmers, provided they have the wherewithal to procure improved breeds of animals with which they can cross with their local animals.

\subsection{Pedigree Selection}

By pedigree of livestock, it connotes the past performance records of their ancestors accumulated over the years which formed the basis for referral purposes whenever the need for use arises. So when an animal is chosen for breeding purpose on the basis of its ancestors' past performance records, then it is pedigree selection that has been used. Take for instance, when a bull born to high milk producing cow is chosen for breeding of dairy cattle, it is pedigree selection that has been used. This is because the bull has been chosen based on the past performance records of its ancestors, but not on its individual performances. According to Williamson and Payne (1978), this technique can be of value only if the pedigree information is complete and easily accessible. This technique is used principally in animal breeding to avoid too close an inbreeding ratio.

\subsection{Artificial Insemination (AI)}

Age and Ahemen (2010) defined artificial insemination (AI) as a process of injecting semen in which spermatozoa are suspended into the vagina of a female animal by means of man-made or artificial devices instead of mating. To do this, a male animal that has reached sexual maturity and has desirable qualities is masturbated with the aid of artificial vagina, which stimulates it to release semen. Use can also be made of electro-ejaculator in collecting semen from male animals for breeding purposes.

Having collected the ejaculated sperms from the male, the semen is then stored in liquid Nitrogen at the temperature of $-196^{\circ} \mathrm{C}$ where it can be maintained for quite a long time until the need for use arises.

Before this stored semen can be introduced into the vagina of a female animal, the heat period, oestrous cycle and ovulation of that particular female animal must be known. As soon as that has been established, semen can be collected with the aid of artificial penis or syringe and injected or introduced into the vagina of a female animal. This checks the risks of infection and veneral diseases, and it is economical because the spermatozoa needed can be transported easily and conveniently from one country to another at low cost. However, it is too scientific for the use of peasant farmers and there are no storage facilities in less developed countries to preserve spermatozoa.

\subsection{Performance Testing}

Performance testing is the actual process of measuring and recording livestock performance in one or more traits. It is not restricted to determining the live weights of livestock at various age ranges, but should be broad enough to cover all economic traits, such as annual sow productivity, meat, egg and milk production. Performance testing records can be reliable and more valid if and only if such records are compared with records of other animals from other farms. Such records are useful both for selecting the high producers and for culling undesirable animals. Performance testing helps to identify the best performing animals and gives information about the breeding value of the sires and dams that produced them (Clayton \& Dyer, 1978).

Performance testing is based on the fact that individual animals differ in their ability to grow rapidly, mature early, convert feeds into meat efficiently and produce high quality of carcasses (Clayton \& Dyer, 1978). According to them, all these traits are inherited but some of them are more heritable than others. In view of the 
foregoing, each livestock farmer should become familiar with the heritability estimates of livestock traits in which he is interested, and in order that he may know where to put his selection emphasis to make the greatest progress.

\subsection{Livestock Breeding Value Evaluation}

Livestock breeding value evaluation is a process of determining the extent to which young potential breeders or breeding stock have breeding value and therefore are physically, mentally, anatomically and physiologically sound enough to withstand breeding and to produce the expected products for which they are kept. Young breeders approaching breeding age should always be evaluated prior to breeding. Bulls for instance, should be 18 months of age when they are evaluated. Boars should be 9 months, while sows should be 6-7 months of age when they are evaluated. It is a good practice to conduct breeding value evaluation because it helps to detect reproductive abnormalities in young potential breeders early enough before breeding season, so that such abnormalities could be nipped in the bud (e.g. needle teeth in gilts and coon footedness in bulls). It also helps in isolating or culling those with severe reproductive problems. For instance, a bull with a single testis or inguinal hernia can be detected and culled, since it has a lessened breeding value. The following are some of the types of livestock breeding value evaluation that can be used:

\subsection{Breeding Soundness Evaluation}

Here, there is a complete or wholistic evaluation of males prior to breeding season. This entails carrying out a wholistic check on the feet and legs, penis or testes and semen of males to ensure reproductive soundness. Besides, there is need to evaluate the ecto and endo-parasitic status of the potential breeders as well as routine immunization, whether or not it has been given to them in order to improve their good health.

\subsection{Visual Evaluation}

This entails meticulous observation of the potential breeders to detect if they have the following deformities of feet and legs:

a. Toed-out and toed-in which prevent them from walking straight on their feet. These can prevent animals from travelling long distances. Of these, toed-in is a more critical condition.

b. Sickle-hocked-which causes lameness in the hind legs due to excessive set. This condition leads to severe soreness during service.

c. Post-legged-a condition in which breeders have hind legs that are too straight. This can affect effective service.

d. Cow-hocked-a condition in which animals ' hind legs are too close (cow-hocked) at the hocks and so have abnormal strains at these joints. When viewed from the rear, bulls should stand on straight legs. Those that are cow-hocked cannot do so, since their legs are too close at the hocks.

e. Bow-legged-a condition in which animals' hind legs are out at the hocks. All these abnormalities prevent smooth movement of the animals during service.

\subsection{Semen Evaluation}

This starts with collection of semen from a male animal through masturbation and use of artificial Vagina or by the use of electro ejaculator. As soon as semen is collected, an operator immediately makes an evaluation of 1 . Colour, which should be whitish, opaque fluid, 2. Volume, which should be 3-4 milliliters, 3. Viscosity, which should be reasonably thick and not watery, and 4 . Motion.

The collected semen is then identified by labeling after which it is placed in an insulated container and sent to the laboratory, where a microscopic evaluation is made to determine motion of semen, concentration, percent alive and abnormalities of the semen such as presence of pus, which gives an indication that the male animal has a veneral disease and needs further attention to determine the case and necessary treatment prior to breeding.

Progeny-testing: This refers to the assessment of the breeding value of an animal on the basis of the performance of its offsprings. Progeny testing mostly makes use of selecting males for breeding because research has shown that males in most livestock species produce many offsprings during their lives than females. Progeny testing is most useful technique to employ where a trait such as milk production is not measurable in mature animal of both sexes, where the heritability of a trait is low, where the breeding unit is large and where the increase in the generation interval, implicitly in the method, is not too pronounced (Williamson \& Payne, 1978). In advanced countries, special testing stations for progeny testing have been established for the selection of pigs, poultry, dairy and beef cattle. At these stations or centres, housing, feeding and general management practices are 
standardized. For practical purposes and from the breeding stand point, if you want to select say, dairy cattle for breeding, the dairy bulls, say two are tested by subjecting 10-20 daughters (heifers) of each bulls to progeny test. This can be done by randomly selecting 10-20 daughters (heifers) of each of the bulls from different herds without reference to the production performances of their dams. The heifers randomly selected must be approximately of the sane age and sexual maturity. They should be brought together in the testing station at least 3 months before parturition and should be retained until after they have completed one lactation. Comparisons between the two bulls can then be made on the basis of performance of the progeny groups at that testing station. Progeny-testing stations should be located where there are enough facilities for good livestock management, particularly where it is possible to demonstrate good husbandry methods to the livestock owners whose animals are under progeny test. The major challenges of progeny test include: high cost of establishing progeny testing stations, high cost of feeding animals under progeny test etc.

\section{Conclusion}

Food security and industrial development are dependent on increased productivity of crops, livestock and fisheries. In the livestock sub-sector, this can be achieved through adoption of animal improvement technologies such as crossbreeding, pedigree selection, progeny testing, artificial insemination, performance testing and livestock breeding value evaluation.

\section{Recommendations}

In order to attain sustainable food security and industrial development in Nigeria, the following recommendations are pertinent:

a. Intensification of awareness campaign to sensitise and conscientise all rural and urban farmers on how to keep farm animals using improved management systems and practices.

b. Rendering of livestock extension services to all categories of farmers on how to practice cross breeding, pedigree selection, performance testing and livestock breeding value evaluation.

c. Establishment of progeny testing stations in every State of the Federation. There may be need to decentralize these to all the 774 Local Government Areas in the country.

d. Subsidizing of livestock feeds, drugs and vaccines in order to make them affordable to all farmers.

\section{References}

Age, A. I., \& Ahemen, T. (2010). Animal improvement strategies. In: Age, A. I. (ed.). Basic Agriculture for Universities in Nigeria. Larigraphics Publishers, Jos. p. 217.

Bawa, G. S., \& Dafwang, I. I. (2000). Pig production for Small Scale Piggeries, NAERLS, A.B.U., Zaira. p. 24.

Clayton, C. O., \& Dyer, I. A. (1978). Commercial Beef Cattle Production. Lead and Febiger, Philadelphia, United States of America. p. 414.

NPC. (2006). National Housing and Population Enumeration Census Report. National Population Commission, Abuja.

Williamson, G., \& Payne, W. J. A. (1978). An introduction to Animal Husbandry in the Tropics (3rd ed.). Butter and Tanner LTD, London. pp. 541-593.

Uza, D. V., Aribido, S., Abubakar, A., \& Ahmed, U. (1999). Transferable Technologies for enhancing Smallholder livestock production. Onavia Printing and Publishing co. LTD., Makurdi. p. 135. 